\title{
PERSPECTIVAS HISTÓRICAS PARA O LAZER E A EDUCAÇÃO NA NATUREZA
}

Recebido em: 13/10/2010

Aceito em: 10/02/2011

Cleber Dias

Universidade Federal de Goiás

Goiânia - GO - Brasil

RESUMO: O propósito deste artigo é analisar a história das concepções e das instituições ligadas à promoção do lazer e da educação por intermédio de práticas corporais em ambientes naturais. O principal argumento do trabalho é que embora alguns importantes acontecimentos sob este aspecto tenham se desdobrado, inegavelmente, apenas muito recentemente, a história de tais iniciativas são mais antigas e remontam, no mínimo, ao século XIX, resultado, portanto, de configurações sociais dinamizadas pela modernidade.

PALAVRAS-CHAVE: História. Atividades de Lazer. Natureza.

\section{HISTORICAL PERSPECTIVES FOR LEISURE AND OUTDOOR EDUCATION}

ABSTRACT: The purpose of this paper is to analyze the history of the ideas and institutions of leisure and outdoor education. The main argument is that, although some major events of history of leisure and outdoor education were only recently, the history of these initiatives are older. They refer to century XIX, result, therefore, social settings impetus for modernity.

KEYWORDS: History. Leisure Activities. Nature.

O interesse por esportes realizados em ambientes naturais tem aumentado consideravelmente nos últimos anos. As estimativas sobre o crescimento no número de adeptos de práticas de lazer e de esportes na natureza é apenas uma demonstração que comprova esse processo. Concomitantemente, tem-se também a intensificação de investigações acadêmicas dedicadas à temática, multiplicando as suas publicações. 
Parte desta literatura especializada tem se ocupado de enfatizar o potencial educativo dessas atividades, ressaltando, quase sempre, sua contemporaneidade. São análises que destacam as experiências na natureza como um lugar privilegiado para a formação e disseminação de valores humanisticamente mais desejáveis, como a solidariedade ou a responsabilidade ambiental. Sem a pretensão de discutir a efetiva capacidade educativa dessas práticas, o objetivo aqui é tão somente analisar a história das concepções e instituições ligadas ao lazer e à educação na natureza. Nesse sentido, vale dizer, a criação de certas entidades dedicadas à promoção da "educação ao ar livre" geralmente é tomada como importante marco cronológico de definição e periodização para o fenômeno. Cita-se, por exemplo, a fundação da Outward Bound em 1941, da Association for Environmental and Outdoor Education em 1954 ou da National Outdoor Leadership School em 1965.

A Outward Bound é o resultado de uma experiência que se deu em primeiro lugar na Inglaterra em meio à Segunda Guerra Mundial. Suas finalidades era a de estimular habilidades necessárias à vida no mar entre novos marinheiros, tentando mesmo responder às necessidades reclamadas por Lawrence Holt, chefe da Blue Funnel Shipping Line, uma companhia da Marinha Mercante. Holt alegava que os novos marinheiros não seriam capazes de sobreviver a situações de naufrágio caso seus barcos fossem atacados por navios alemães. Segundo se dizia à época, faltava-lhes "experiência de vida", pois os marinheiros mais velhos, diferentemente, teriam desenvolvido suas habilidades práticas no confronto direto em situações exigentes e de dificuldade real. Foi assim que se desenvolveu um programa de treinamento chamado já naquela ocasião Outward Bound - um termo náutico mobilizado para descrever o 
momento em que o navio deixa a segurança do porto em direção aos desafios do mar aberto.

O formato final dessa iniciativa, no entanto, era uma adaptação de experiências que vinham sendo amadurecidas há alguns anos já sob a direção de um educador alemão de nome Kurt Hahn. Nascido em 1886, Hahn havia sido, na década de 1920, um dos fundadores da Salem Schulem, uma escola experimental que buscava a formação integral dos seus alunos através, justamente, da promoção do aprendizado através da experiência direta. Lá ele pode exercitar e desenvolver parte dos seus ideais pedagógicos. No início da década de 1930, depois de declarações públicas contra a ascensão de Hitler e do Estado Nazista, Hahn se exilou na Grã-Bretanha. Em 1934, ano seguinte a sua chegada, cria uma nova escola, a Gordonstoun, sediada em um castelo abandonado na Escócia e que inicialmente atenderia a três alunos apenas. Nos anos seguintes, Hahn segue desenvolvendo e aprimorando suas propostas educativas buscando maneiras de tornar-las mais acessíveis. Nesse sentido, concebe um esquema por meio dos quais jovens poderiam desenvolver suas habilidades físicas e ampliar suas capacidades como a confiança e a autodisciplina através de uma expedição de 28 dias que deveria funcionar como um pequeno curso de verão; espécie de "experiência de imersão", "inesquecível", concentrando desafio e aventura a fim de incentivar o aprendizado da vida ao ar livre (THOMAS, 1990).

Nesse ínterim, Lawrence Holt, que já estava interessado nas idéias de Hahn, firmou finalmente parceria com o educador alemão e assim estabeleceu-se uma escola para marinheiros na cidade costeira de Aberdovey, na Inglaterra, que recebeu o nome de Outward Bound. Entre 1950 e 1955 duas novas escolas foram inauguradas: uma em Eskdale e outra em Ullswater, respectivamente. Nos anos seguintes, novas escolas 
foram sendo inauguradas na Austrália e na Alemanha (1956). Entre 1962 e 1963 uma escola foi inaugurada nos Estados Unidos (no Colorado, mais especificamente), com mais cinco escolas sendo criadas naquele país até o fim dos anos 1960.

Atualmente, a Outward Bound é uma entidade internacional que conta com 52 escolas espalhadas por 32 países de todos os continentes (a do Brasil, primeira da América do Sul, foi implementada no ano 2000). Estima-se que em seus cursos já passaram mais de 2 milhões de pessoas ao longo dos seus mais de 60 anos de existência. De certo modo, sua experiência ajudou a promover toda uma indústria outdoor, além, é claro, do próprio estabelecimento e popularização da noção de educação ao ar livre. Sob este último aspecto, a Outward Bound é reconhecida como um exemplar bastante paradigmático. Seus princípios forneceram um modelo que foi mais ou menos seguido por outras importantes e influentes instituições de educação ao ar livre que vieram depois, como é o caso da National Outdoor Leadership School, por exemplo. Criada nos Estados Unidos em 1965 por Paul Petzoldt, um instrutor da Outward Bound, a National Outdoor Leadership School ganhou maiores proporções de forma relativamente rápida. Depois de uma aparição em um programa de televisão e de uma reportagem na revista Life, a organização parece ter adquirido considerável visibilidade. Assim, o número de alunos nos seus programas saía de 250 em 1969 para 750 em 1970. Na temporada entre 1976 e 1977 esse número já havia alcançado o patamar de mais de 1.500 estudantes, segundo dados fornecidos pela própria instituição (WOODS, 2009).

A década de 1970, aliás, testemunhou um notável crescimento de atividades dessa natureza em vários lugares do mundo, especialmente nos Estados Unidos. Em 1971 criava-se o Projeto Adventure, idealizado por Jerry Pieh, filho de Bob Pieh, fundador da escola da Outward Bound de Minessota, Estados Unidos. A idéia era 
aplicar os princípios e fundamentos da Outward Bound em atividades de uma escola convencional. Em 1974, o Projeto Adventures passou a dispor dos recursos de um fundo financeiro do governo federal norte-americano e foi implementado em mais de 400 escolas. Em 1975, mais ou menos no mesmo sentido, fundava-se a Wilderness Education Association e a Association for Experiential Education. Entre 1970 e 1975 estabeleceram-se mais de 45 programas norte-americanos de educação ao ar livre (ATTARIAN, 2002).

Com efeito, tais dinamizações parecem estar profundamente articuladas com o sucesso do movimento ambientalista internacional, que alcançou notabilidade pública exatamente entre o início dos anos de 1960 e o final dos de 1970. A criação, crescimento e proliferação de organizações de combate à poluição e a devastação ambiental é um bom indício nesse sentido. Desde a década de 1960 há um considerável aumento no número e no alcance de organizações dessa natureza. "Em 1969-1970, o crescimento anual do número de membros dos cinco maiores grupos conservacionistas americanos era de 16\% a 18\%" (MCCORMICK, 1992, p. 79). Somente nos Estados Unidos e considerando-se apenas cinco entidades, o número total de adeptos saltou de 593 em 1968 para 1.733 em 1984. Na Grã-Bretanha, passou-se de 277 para 2.047 no mesmo período. Somente o Sierra Club, tido como um dos mais influentes e tradicionais grupos ambientais norte-americanos, viu seu número de membros aumentar de sete para setenta mil. No período que vai de 1966 a 1970 o número de participantes triplicou (MCCORMICK, 1992, p. 79).

Em 1961, por iniciativa de cientistas, foi criado na Suíça o WWF (Worldwide Fund for Nature - Fundo Mundial para a Natureza), que logo nos seus três primeiros anos de existência arrecadou quase dois bilhões de dólares. Atualmente, a WWF tem 
quase 5 milhões de afiliados, em 96 países com 700 projetos, que contam com um investimento total de aproximadamente 329 milhões de dólares por ano. No início de 1970, no mesmo sentido, fundou-se o Greenpeace, que se projetou através de ações espetaculares, lançando pequenos botes na frente de enormes navios baleeiros ou estendendo faixas de protesto em chaminés de grandes indústrias, tornando-se conhecido internacionalmente. Já em 1985, “havia escritórios do Greenpeace em 17 países, com um número total de um milhão e duzentos mil membros” (MCCORMICK, 1992, p. 79).

A criação de partidos verdes, o aumento no seu número de filiados e seu relativo sucesso em algumas eleições também são testemunhos da "voga do verde" que entrou em marcha no mundo contemporâneo. O primeiro partido desse gênero foi criado na Nova Zelândia em 1972, seguido nos dois anos subseqüentes pela Grã-Bretanha e França, respectivamente. Nos anos seguintes, viu-se, progressivamente, o mesmo acontecer na Bélgica, Alemanha, Suíça, Luxemburgo, Finlândia, Suécia, Áustria, Irlanda, Holanda e Itália, de modo que entre o final dos anos 70 e o início dos anos 80, partidos ecológicos haviam sido criados em mais de dez países. Atualmente, em todo mundo, contabilizam-se mais de 120. Na França, o número de filiados saltou de 1.700 para 4.400 no curto espaço de tempo entre 1988 e 1989 (ALPHANDÉRY, BITOUN, DUPONT, 1992, p. 64).

\section{Modernidade, lazer e educação na natureza}

Do ponto de vista acadêmico e interpretativo, destaca-se, comumente, a dimensão atual e hodierna do processo de institucionalização da idéia de recorrer à natureza como um veículo de educação (PICKETT, POLLEY, 2001; MARINHO, 
INÁCIO, 2007). Teoricamente, portanto, predomina o entendimento de que é um cenário social "pós-moderno" o vetor e o catalisador de práticas na natureza (com finalidades educativas ou não, como é o caso também do ecoturismo).

De fato, a própria cronologia da fundação de instituições diretamente ligadas à educação ao ar livre, como a que acabamos de sumariar acima, autoriza a depreender conclusões nessa direção. O efetivo crescimento dessas atividades na segunda metade do século XX sugere mesmo tratar-se de um fenômeno recente e atual. Nessa época, como vimos, ações de educação ao ar livre se intensificaram em várias partes do mundo.

Mas em que medida realmente seria correto identificar a origem deste fenômeno nesse período? Quando se situa a origem do surgimento das concepções e das primeiras instituições ligadas à promoção da educação por intermédio de práticas corporais em ambientes naturais?

Nosso argumento aqui é que embora alguns importantes acontecimentos tenham se desdobrado, inegavelmente, apenas muito recentemente, a gênese de tais iniciativas são mais antigas; resultado de configurações sociais dinamizadas pela modernidade e não pela pós-modernidade. Assim, poderíamos recuar um pouco mais no tempo e citar, de início, o escotismo, que desde 1907 vem formalizando princípios de educação nãoformal com ênfase nas atividades ao ar livre. Mais do que simplesmente constituir-se como uma origem remota dos fundamentos de uma educação na natureza, o movimento dos Scout Boys estabeleceu, através de uma complexa teia de influências, relações bem diretas com o posterior desenvolvimento do uso da natureza para educação.

Kurt Hahn, por exemplo, fundador da Outward Bound, afirmava publicamente que seus métodos não traziam em si nada de novo ou original. Ao contrário, dizia tratar- 
se simplesmente da retomada de idéias que havia apreendido do passado. Entre elas, citava e recorria explicitamente as de Baden Powell.

Baden Powell era um oficial do exército inglês nascido em Londres em 1857, que como muitos da sua geração, teve o costume de passar as férias em acampamentos durante a infância. Quando adulto, já militar de carreira, escreveu um livro intitulado Aids to Scouting, que alcançou relativo sucesso não só entre o público militar, mas também entre jovens interessados em informações sobre como acampar e sobreviver em ambientes selvagens, chegando a ser adotado como compêndio educacional. Em 1907, motivado pela acolhida do livro e incentivado por outras pessoas, decidiu então organizar um acampamento experimental na Ilha de Brownsea, na Inglaterra, reunindo 20 rapazes com idade entre 12 e 16 anos. Realizaram-se tarefas que estimulassem o desenvolvimento de virtudes como lealdade, companheirismo, disciplina e obediência, além do ensino de técnicas de primeiros-socorros ou conhecimentos sobre sobrevivência na selva em geral. Entusiasmado com o resultado, Powell escreveu um livro que adaptava os métodos militares de exploração à formação dos jovens. Surgiu assim o famoso livro Escotismo para rapazes (Scouting for Boys), pedra angular do Movimento Escotista. Publicado inicialmente em fascículos quinzenais, o livro conheceu grande sucesso e em 1908 foi fundado oficialmente o Movimento Escoteiro. Dois anos depois haveria já mais de 120.000 escoteiros em toda a Grã-Bretanha, e em 1912 a Coroa Inglesa reconheceria a utilidade pública da organização. Atualmente a organização congrega mais de 30 milhões de escoteiros em todo o mundo, sendo, aproximadamente, mais de 50 mil apenas no Brasil.

Muitos dos princípios do Movimento Escoteiro, que eram conhecidos e foram deliberadamente aproveitados por Kurt Hahn, estavam sedimentados de maneira muito 
mais sólida e profunda nos hábitos e costumes dos ingleses. Isso explica, em parte, por que a fundação do Escotismo se difundiu tão rapidamente por toda a Grã-Bretanha. Desde os meados do século XIX vê-se naquele país instituições ligadas à organização de passeios e viagens à natureza com considerável nível de alcance e popularidade. Já em 1865, por exemplo, tinha-se um grupo ambientalista que reivindicava mais espaços naturais para o lazer da população (MCCORMICK, 1992). Da mesma forma, clubes de Geologia, Ornitologia ou de História Natural cumpriam também essas funções, de modo que "por volta da década de 1880, havia várias centenas de sociedades de história natural e clubes de campo no interior que reuniam cerca de cem mil membros" (ibid., p. 23).

Antes disso ainda, por volta dos anos de 1840, desde os primórdios da sua fundação, a ACM - Associação Cristã de Moços (em inglês, YCMA, The Young Men's Christian Association) -, organizava já caminhadas a pé por florestas e montanhas como uma das atividades do seu programa educativo (RAUCH, 2001, p. 124).

A Inglaterra era realmente um palco privilegiado para tais manifestações. $\mathrm{O}$ pioneiro desenvolvimento de estruturas propriamente modernas naquele país criou condições para que uma nova sensibilidade, igualmente moderna, fosse brotando e induzindo o surgimento de novas práticas, mais condizentes e compatíveis com aquela estrutura de sentimentos. Nesse sentido, o Grand Tour, praticado pelos ingleses ricos ou bem-nascidos desde o final do século XVII e de maneira progressivamente mais disseminada ao longo de todo o século XVIII, pode ser aqui tomado como uma matriz remota e moduladora dos gostos e predileções que entrariam em ação nos atua modos de se usufruir à natureza para o lazer e para a educação. De acordo com Valéria Salgueiro (2001): 
Viagens em busca de deleite e emoção, visando ao aprimoramento pessoal e fundadas em categorias de apreciação estética começaram a acontecer em escala crescente exatamente quando a o centro irradiador do desenvolvimento capitalista - a Europa - acelerou seu curso de desenvolvimento na indústria e na racionalização do trabalho, ao qual estiveram sempre ligados os conceitos de tempo livre e de ócio, em oposição ao tempo do trabalho (p. 290).

Em outras palavras, com estreita conexão com as transformações do Iluminismo e da Revolução Industrial, surge um tipo de viajante que busca o conhecimento de novos lugares por prazer e por amor à cultura. Entre as suas motivações figura, precisamente, o gosto pela natureza sublime, isto é, pela experiência estética do êxtase diante da paisagem grandiosa. O Grand Tour, nesse sentido, foi "responsável em grande dose pelo culto ao cenário natural” (SALGUEIRO, 2001, p. 305).

Mais que isso, no entanto, tratava-se de uma viajem que se justificava por motivações de ordem estética, artística e cultural, onde se aprenderia novos idiomas; conhecer-se-ia ruínas, monumentos e obras de artes; confrontar-se-ia paisagens com textos da literatura clássica e se daria vazão aos impulsos do humanismo da época que cultuava o passado e o conhecimento das civilizações da Antiguidade. O Grand Tour, enfim, fortemente associado ao início moderno das viagens à natureza por prazer, era "parte essencial da educação de todo o inglês de posse" (SALGUEIRO, 2001, p. 291).

Embora a Inglaterra fosse, de fato, o grande fornecedor de modelos do lazer na natureza, fenômenos análogos podem ser identificados em outros lugares da Europa Ocidental, especialmente na França e na Alemanha. A partir de 1875, o Clube Alpino Francês daria início à organização regular das "caravanas escolares", excursões à montanha endereçadas aos jovens estudantes com o propósito de promover-lhes a educação, e que rapidamente entram em voga entre os estudantes do liceu, alcançando, em média, o número de "uma dezena de caravanas por ano" (RAUSCH, 2001, p. 125). 
Na Alemanha, a partir de 1890, vê-se o desenvolvimento do movimento Wandervögel, que afirmava o gosto de passeios a pé pelas florestas. Em 1903 seriam contabilizadas mais de quatrocentas seções de Wandervögel por todo o país e em 1914 seriam mais de quarenta e cinco mil. Paralelamente, e no mesmo sentido, desenvolvemse também Associações de Caminhantes (Wanderverein), que dariam origem mais tarde a Federação de Caminhantes Alemães (Bund Deutsche Wanderer). Não por acaso, atividades de lazer e de esportes na natureza constituem uma das mais bem acabadas expressões da mentalidade alemã de divertimentos, onde acampamentos, alpinismo ou férias no campo de um modo geral são opções que gozam de extrema popularidade. Kurt Hahn, portanto, estava imerso nessa cultura e certamente compartilhava desse imaginário, sendo, evidentemente, por ele influenciado. Ao mesmo tempo, em função de experiências e aprendizagens muito particulares, Hahn pôde ser também um autêntico inventor de novas abordagens educacionais, que enfatizavam e destacavam o lugar de vivências na natureza. Continuidade e ruptura, inovação e permanência estão aqui em constante tensão. É como nos afirma o historiador italiano Carlo Ginzburg (1987), a cultura é uma jaula flexível. "Assim como a língua, a cultura oferece ao indivíduo um horizonte de possibilidades latentes - uma jaula flexível e indivisível dentro da qual se exercita a liberdade condicionada de cada um" (p. 27). A cultura e a história então, com suas coerções necessárias à própria vida em sociedade, oferecem um horizonte de possibilidades cujo limite é a liberdade individual, relativa e condicionada.

Assim, parte das idéias do homem que é tido como o grande precursor das noções de educação ao ar livre está assentada em uma longa tradição que foi se constituindo a partir do acúmulo de experiências, bem como através do ininterrupto intercâmbio de práticas e pensamentos entre pessoas e lugares. Podemos dizer, portanto, 
que as concepções de Kurt Hahn, em certo sentido, constituem-se como a expressão de costumes, idéias, valores e cosmologias herdadas todas do passado, sem, contudo, deixar de ter estabelecido suas próprias e criativas relações com as peculiaridades e demandas do seu momento histórico.

\section{Considerações Finais}

Do ponto de vista teórico, analítico ou interpretativo, o desafio que se apresenta aqui para o estudo do lazer na natureza em geral, bem o de suas possíveis interfaces com o campo educativo, é o de um aprofundamento mais sistemático em reflexões que tenham em conta, especificamente, as suas dimensões históricas.

Em resumo, a idéia que fundamentou esse artigo foi a de que podemos acertadamente situar no século XIX - senão no quartel final do século XVIII - os primórdios daquilo que chamaríamos atualmente de lazer na natureza e também, em conseqüência, de "educação ao ar livre". Esses são fenômenos que parecem o resultado de práticas oitocentistas, que se ainda não se configuravam àquela época claramente nesses termos, no mínimo ofereceram um vocabulário, uma gramática e uma grade de interpretação que se constituíram como as condições de possibilidade delas mesmas.

O advento de um mundo moderno mobilizou novas concepções sobre uma série de aspectos da vida social. Outra concepção de corpo, por exemplo, veio à baila nessa época. Era um corpo que surgia como veículo de ações mensuráveis e calculáveis, produtor de forças previsíveis e contabilizadas, conforme disse Georges Vigarello (2003). No mundo luso-brasileiro, desde os fins do século XVIII, inovações no saber médico, em larga medida conformadas ao desenvolvimento nas filosofias e físicas mecanicistas, tendiam, cada vez mais, a valorizar uma concepção de corpo-máquina. 
Visto e tido como uma grande tubulação de canos e vasos, o corpo seria então o organismo a canalizar os líquidos corporais. A saúde, nessa perspectiva, era resultado da possibilidade de livre circulação dos fluídos, enquanto a doença seria justamente o resultado do seu bloqueio. Nesse contexto, figuras como Francisco de Mello Franco, médico brasileiro graduado em Portugal, passavam a defender a ação transformadora do exercício físico, bem como os efeitos positivos do "ar fresco" ou do contato com a natureza de modo geral (ABREU, 2006). Articuladas, essas convicções desaconselhavam a vida muito próxima das cidades, ao mesmo tempo em que animavam atividades em meio à natureza em geral (DIAS, 2010).

De maneira talvez mais abrangente, o tempo também passou a ser alvo de outras formas de relacionamento com o advento da modernidade. Predominaria dali em diante uma concepção de tempo bem diferente daquela da Idade Média. Tratava-se do "tempo do mercador", como chamou Jacques Le Goff (1979): uma concepção de tempo regida pelos relógios, marcada pelas necessidades dos negócios, movido pelo desejo de lucro. Era o tempo mercadoria. Da mesma forma, a maneira como se olhava à natureza também passaria por grandes transformações. A disseminação de uma mentalidade científica, iluminista, reduz os constrangimentos diante da natureza. Montanhas, praias, florestas e desertos pouco a pouco deixam de ser vistos como moradas de animais monstruosos e, em contrapartida, uma nova maneira de perceber as paisagens naturais vai se edificando (CORBIN, 1989; MACFARLANE, 2005). Na esteira disso tudo, quase que de maneira integrada, práticas corporais em ambientes naturais vão se modulando.

Ao propormos que os princípios de organização dos esportes na natureza já estavam bem definidos desde o século XIX não estamos negando a atualidade que a interface entre esporte e meio ambiente assume nos dias de hoje. Tampouco estamos desconsiderando as reconfigurações do campo esportivo. A questão central é que os 
elementos de descontinuidade, de ruptura e de inovação, devem ser analisados articuladamente com as "estruturas de longa duração. Estamos, portanto, defendendo a idéia de que as inovações nos hábitos esportivos que os esportes na natureza trazem consigo se inserem em um longo processo de desenvolvimento histórico, que deve ser seriamente considerado para fins de uma compreensão mais ampliada dos seus sentidos e significados no quadro contemporâneo (DIAS, MELO, ALVES JUNIOR, 2007, p. 365).

\section{REFERENCIAS}

ABREU, Jean Luiz Neves. A Educação física e moral dos corpos : Francisco de Mello Franco e a medicina luso-brasileira em fins do século XVIII. Estudos IberoAmericanos, Porto Alegre, v. 32, n. 2, p. 65-84, dez. 2006.

ALPHANDÉRY, Pierre; BITOUN, Pierre; DUPONT, Yves. O equívoco ecológico: riscos políticos da inconseqüência. São Paulo: Brasiliense, 1992.

ATTARIAN, Aram. Trends in outdoor adventure education. In: ASSOCIATION OF OUTDOOR RECREATION AND EDUCATION. Annual International Conference on Outdoor Recreation and Education: Preserving the Past, Protecting the Future. 16, Proceedings... Bloomington: Association of Outdoor Recreation and Education, 2002, p. $28-40$.

CORBIN, Alain. O território do vazio. São Paulo: Companhia das Letras, 1989.

DIAS, Cleber. História do lazer na natureza no Rio de Janeiro entre 1779 e 1838: um estudo de caso. Tese (Doutorado) - Universidade Estadual de Campinas, Faculdade de Educação Física, Campinas, 2010.

DIAS, Cleber; MELO, Victor; ALVES JUNIOR, Edmundo. Os estudos dos esportes na natureza: desafios teóricos e conceituais. Revista Portuguesa de Ciências do Desporto, Lisboa, v. 7, n. 3, p. 358-367, dez. 2007.

GINZBURG, Carlo. O queijo e os vermes. São Paulo: Companhia das Letras, 1987.

LE GOFF, Jacques. Na Idade Média: tempo da Igreja e tempo do mercador. In: Para um novo conceito de Idade Média. Lisboa: Estampa, 1979, p. 61-73.

MAC FARLANE, Robert. Montanhas da mente. Rio de Janeiro: Objetiva, 2005.

MARINHO, Alcyane; INÁCIO, Humberto. Educação física, meio ambiente e aventura: um percurso por vias instigantes. Revista Brasileira de Ciências do Esporte, Campinas, v. 28, n. 3, p. 55-70, maio 2007.

McCORMICK, John. Rumo ao paraíso: a história do movimento ambientalista. Rio de Janeiro: Relume Dumará, 1992. 
PICKETT, Bronte; POLLEY, Scott. Investigating the history of outdoor education in South Australia. Australian Journal of Outdoor Education, v. 5, n. 2, p. 49-53, 2001.

RAUCH, André. As férias e a natureza revisitada (1830-1939). In: CORBIN, Alain (ed.). História dos tempos livres. Lisboa: Teorema, 2001, p. 93-135.

SALGUEIRO, Valéria. Grand Tour: uma contribuição à história do viajar por prazer e por amor à cultura. Revista Brasileira de História. São Paulo, v. 22, n. 44, p. 289-310, 2001.

THOMAS, James. Kurt Hahn and the aims of education. Journal of Experiential Education, v. 13, n. 1, p. 6-13, 1990.

VIGARELLO, Georges. A invenção da ginástica no século XIX: movimentos novos, corpos novos. Revista Brasileira de Ciências do Esporte, Campinas, v. 25, n. 1, p. 920, set. 2003.

WOODS, Henry. Nols history. National Outdoor Leadership School. Disponível em: http://www.nols.edu/about/history/nols_history.shtml. Acesso em: 21 jan. 2009.

\section{Endereço do Autor:}

Cleber Dias

Rodovia Goiânia - Nerópolis, Km-12,

Campus Samambaia - Caixa Postal: 131

CEP: 74001 - 970 - Goiânia - GO

Endereço Eletrônico: cag.dias@bol.com.br 